\title{
A Compact Tetrathiafulvalene-Benzothiadiazole Dyad and its Highly Symmetrical Charge-Transfer Salt: Ordered Donor $\pi$-Stacks Closely Bound to Their Acceptors
}

\author{
Yan Geng, ${ }^{[a]}$ Raphael Pfattner, ${ }^{[b, c]}$ Antonio Campos, ${ }^{[b]}$ Jürg Hauser, ${ }^{[a]}$ Vladimir Laukhin,,$[,,, d]$ \\ Joaquim Puigdollers, ${ }^{[\mathrm{e}]}$ Jaume Veciana, ${ }^{[\mathrm{b}, \mathrm{c}]}$ Marta Mas-Torrent, ${ }^{*[\mathrm{~b}, \mathrm{c}]}$ Concepció Rovira, ${ }^{[\mathrm{b}, \mathrm{c}]}$ 'Silvio \\ Decurtins, ${ }^{[a]}$ and Shi-Xia Liu* ${ }^{[a]}$
}

\begin{abstract}
A compact and planar donor-acceptor molecule 1 comprising tetrathiafulvalene (TTF) and benzothiadiazole (BTD) has been synthesised and experimentally characterised by structural, optical and electrochemical methods. Solution processed and thermally evaporated thin films of 1 have also been explored as active material in organic field-effect transistors (OFETs). For these devices, a hole field-effect mobility of $\mu_{\mathrm{FE}}=(1.3$ $\pm 0.5) \times 10^{-3} \mathrm{~cm}^{2} / \mathrm{Vs}$ and of $\mu_{\mathrm{FE}}=(2.7 \pm$ $0.4) \times 10^{-3} \mathrm{~cm}^{2} / \mathrm{Vs}$ could be determined
\end{abstract}

for the solution processed and thermally evaporated thin films, respectively. An intense intramolecular charge-transfer (ICT) transition around $495 \mathrm{~nm}$ dominates the optical absorption spectrum of the neutral dyad, which also shows a weak emission from its ICT state. The iodine induced oxidation of 1 leads to a partially oxidised crystalline charge-transfer (CT) salt $\left\{(\mathbf{1})_{2} \mathrm{I}_{3}\right\}$, and eventually also to a fully oxidized compound $\left\{\mathbf{1 I}_{3}\right\} \cdot 1 / 2 \mathrm{I}_{2}$. Single crystals of the former CT compound, exhibiting a highly symmetrical crystal structure, reveal a fairly good room temperature electrical conductivity of the order of $2 \mathrm{~S} \mathrm{~cm}^{-1}$. The one-dimensional spin system bears compactly bonded BTD acceptors (spatial localisation of LUMO) along its ridge.

Keywords: donor-acceptor
systems $\bullet$ tetrathiafulvalene-
benzothiadiazole $\bullet$ charge-transfer
salt $\bullet$ electrical conductivity $\bullet$
organic field-effect transistor

\section{Introduction}

Introducing electron donor (D) and acceptor (A) units together into a planar $\pi$-conjugated molecular backbone is a promising strategy to obtain a pronounced electrochemical amphotericity and strong photoinduced intramolecular charge-transfer transitions within the resulting fused dyad. Herein, this paper puts forward a study of a compact $\pi$-conjugated molecule, which results from fusing tetrathiafulvalene (TTF) and 2,1,3-benzothiadiazole (BTD) into a single planar molecular structure, namely the tetrathiafulvalenebenzothiadiazole (TTF-BTD) dyad 1 (Figure 1a). As is well known,

[a] Dr. Yan Geng, Dr. Jürg Hauser, Dr. Shi-Xia Liu, Prof. Silvio Decurtins Departement für Chemie und Biochemie Universität Bern

Freiestrasse 3, CH-3012 Bern, Switzerland

Fax: (+) 41316314399

E-mail: liu@dcb.unibe.ch

[b] Dr. Raphael Pfattner, Antonio Campos, Prof. Vladimir Laukhin, Prof. Jaume Veciana, Dr. Marta Mas-Torrent, Prof. Concepció Rovira Institut de Ciència de Materials de Barcelona (ICMAB-CSIC) Campus UAB

08193 Bellaterra, Spain

Fax: (+) 34935805729

E-mail:mmas@icmab.es

[c] Dr. Raphael Pfattner, Prof. Vladimir Laukhin, Prof. Jaume Veciana, Dr. Marta Mas-Torrent, Prof. Concepció Rovira

Networking Research Center on Bioengineering

Biomaterials and Nanomedicine (CIBER-BBN)

08193 Bellaterra, Spain

[d] Prof. Vladimir Laukhin

Institució Catalana de Recerca i Estudis Avançats (ICREA)

08010 Barcelona, Spain

[e] Dr. Joaquim Puigdollers

Dept. Enginyeria Electrònica

Universitat Politècnica Catalunya

08034 Barcelona, Spain
TTF and its derivatives ${ }^{[1-5]}$ are used as strong $\pi$-donors mainly in the field of organic conductors and superconductors, ${ }^{[1]}$ as $p$-type organic semiconductors in organic field-effect transistors (OFETs) ${ }^{[5]}$ and as electron donor units in D-A ensembles. Thereby, these building blocks favour the spatial localisation of the highest occupied molecular orbital (HOMO) within the molecular ensembles. ${ }^{[2-4]}$ Equally, the fused bicyclic BTD ${ }^{[6]}$ molecule has become a key ingredient in the design of new organic semiconductors where it is often embedded in simple $\pi$-conjugated structures or polymers, whereby its electron-deficient character serves to stabilise and spatially localise the lowest unoccupied molecular orbital (LUMO), hence it can function as an $E_{\mathrm{LUMO}}$ lowering $\pi$-extender.

Recently, we reported the first synthesis and characterization of some TTF-BTD derivatives. ${ }^{[7]}$ As a continuation of previous studies, we describe herein its simple prototype in form of the compact TTFBTD dyad 1, which bears no extra substituents on the $\pi$-conjugated backbone. Besides its structural, optical and electrochemical characterisation, this material has been investigated as semiconductor in OFETs. Although it is widely known that devices based on $\pi$-conjugated polymers with aromatic and/or heteroaromatic backbones as active layers have shown a high OFET performance, soluble molecular semiconductors are currently also attracting interest. ${ }^{[8]}$ Prime examples are soluble pentacene derivatives ${ }^{[9 a]}$ or benzothieno[3,2-b][1] benzothiophene derivatives ${ }^{[9]}$ showing field-effect mobility values of the order of $10 \mathrm{~cm}^{2} / \mathrm{Vs}$. TTFs are also attracting great interest in this field since they are usually soluble in common organic solvents and they have also shown to exhibit high OFET mobilities. ${ }^{[10]}$ In addition, recently it has been reported that TTF based dyads reveal ambipolar OFET characteristics. ${ }^{[11]}$ Therefore, it is worth examining more closely the OFET characteristics based on active layers constructed with thin films of this new dyad compound $\mathbf{1}$.

Furthermore, the oxidation of $\mathbf{1}$ has been probed and the point that can be made is that a partially oxidised crystalline chargetransfer $(\mathrm{CT})$ salt with a simple stoichiometry $\left\{(\mathbf{1})_{2} \mathrm{I}_{3}\right\}$ is formed. 
This is an interesting finding because not only single crystals with a highly symmetrical molecular structure can be grown, but also a novel case is given in that the wires formed by regular $\pi$-stacks of $\mathrm{TTF}^{+0.5}$ bear compactly bonded BTD acceptors representing the LUMO localisation along their ridges (Figure 1b). A further point is that these regular and linear $\pi$-stacks of $\mathrm{TTF}^{+0.5}$ are well segregated and lie parallel in the crystalline bulk material, thus forming a highly symmetrical 1D spin system (Figure 1c). This observation is significant because it is well established that the electronic structure of conducting/semiconducting materials is greatly dependent on the molecular stacking types. ${ }^{[12]}$ In the actual case, what we wish to emphasise is that single crystals of this CT salt reveal a fairly high room temperature electrical conductivity of the order of $2 \mathrm{~S} \mathrm{~cm}^{-1}$. Finally, it is demonstrated, that a fully oxidised CT compound $\left\{(\mathbf{1})_{2} \mathrm{I}_{3}\right\}$ could also be characterised by single crystal structure determination.

a)<smiles>C1=CSC(=C2Sc3cc4nsnc4cc3S2)S1</smiles>

b)

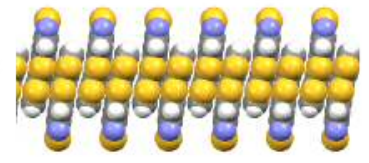

c)

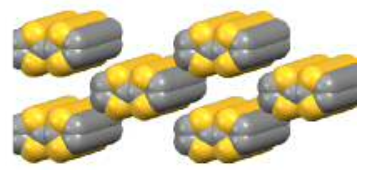

Figure 1. a) Molecular structure of TTF-BTD (1); b) $\left\{(\mathbf{1})_{2} \mathrm{I}_{3}\right\}$ : a wire of $\mathrm{TTF}^{+0.5} \pi$-stacks bearing compactly bonded BTD acceptors along its ridge; c) $\left\{(\mathbf{1})_{2} \mathrm{I}_{3}\right\}$ : illustration of fragments of segregated parallel $\pi$-stacks of TTF $^{+0.5}$ in the crystalline solid.

\section{Results and Discussion}

Synthesis: As illustrated in Scheme 1, the target compound TTFBTD (1) was obtained by a phosphite-mediated cross-coupling reaction of the corresponding ketone precursor 3 with vinylene trithiocarbonate. The transformation of compound $\mathbf{2}$ to the precursor 3 was accomplished in good yield in the presence of $\mathrm{Hg}(\mathrm{OAc})_{2}$. By slow diffusion of iodine into a solution of $\mathbf{1}$, the crystalline chargetransfer salts $\left\{(\mathbf{1})_{2} \mathrm{I}_{3}\right\}$ and $\left\{\mathbf{1}_{3}\right\} \cdot 1 / 2 \mathrm{I}_{2}$ were obtained. The new compounds have been fully characterised.

$$
\mathrm{S}_{\mathrm{S}}^{\mathrm{S}}=\mathrm{N}_{\mathrm{N}}^{\mathrm{N}} \stackrel{\mathrm{Hg}(\mathrm{OAC})_{2}}{\longrightarrow} \mathrm{O}=\mathrm{S}_{\mathrm{S}}^{\mathrm{S}}
$$

Scheme 1. A synthetic route to the TTF-BTD dyad $\mathbf{1 .}$

Crystal structures of TTF-BTD (1): Red coloured single crystals for X-ray analysis, with a thin plate morphology, were grown by slow evaporation of a $\mathrm{CH}_{2} \mathrm{Cl}_{2}$ or $\mathrm{CH}_{2} \mathrm{Cl}_{2} / \mathrm{MeOH}(1: 1)$ solution of 1 giving rise to two solvate free polymorphs $1 \alpha$ and $1 \beta$.

In the former case, 1 crystallises in the triclinic space group $P-1$ (Table 1). The asymmetric unit encompasses one complete molecule, thus all atoms lie on general positions. An ORTEP drawing of $\mathbf{1}$ is shown in Figure 2. The molecule is nearly planar; the rms deviation from a least-squares plane through all atoms is $0.0375 \AA$. The planar molecules are arranged in layers parallel to $\left(\begin{array}{lll}9 & 1 & 1\end{array}\right)$, for example inclined by $16.7^{\circ}$ to $\left(\begin{array}{lll}1 & 0 & 0\end{array}\right)$, showing within these layers short intermolecular $\mathrm{S} \cdots \mathrm{S}$ contacts of $3.464 \AA(\mathrm{S} 3 \cdots \mathrm{S} 4), \mathrm{N} \cdots \mathrm{S}$ contacts of $3.226 \AA(\mathrm{N} 2 \cdots \mathrm{S} 5)$ and $\mathrm{C} 6 \mathrm{H} 6 \cdots \mathrm{S} 2$ hydrogen bonds of $2.839 \AA$ (Figure $\mathrm{S} 1$ ); the layer to layer distance (best plane to best plane) is $3.441 \AA$.

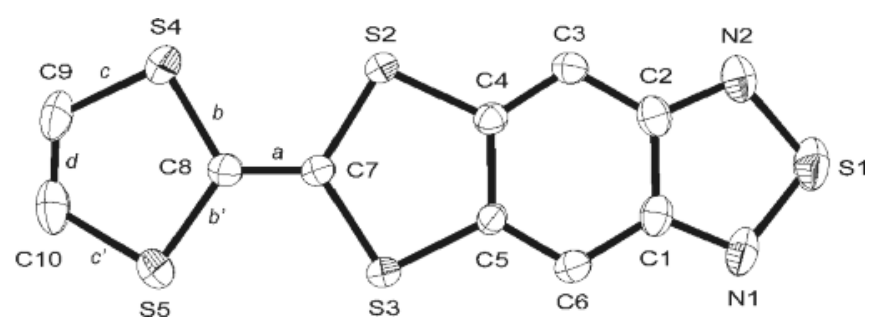

Figure 2. ORTEP drawing and atomic numbering scheme of TTF-BTD (1) in the triclinic space group $P$-1. Ellipsoids are set at $50 \%$ probability; hydrogen atoms have been omitted for clarity.

Interestingly, while using a mixture of solvents, namely $\mathrm{CH}_{2} \mathrm{Cl}_{2} / \mathrm{MeOH}$ (1:1), 1 crystallises in a solvate free form in the monoclinic space group $P 2_{1} / \mathrm{c}$ (Table 1). The asymmetric unit of this modification now contains two crystallographically independent molecules (1A and 1B), whereby all atoms lie on general positions. An ORTEP drawing of both molecules is shown in Figure S2. The molecules are slightly bent; the rms deviations from a least-squares plane through all atoms are $0.2949 \AA$ for $\mathbf{1 A}$ and $0.1664 \AA$ for $\mathbf{1 B}$. The molecules $\mathbf{1 A}$ and $\mathbf{1 B}$ are alternatingly stacked along the $\mathrm{b}$ axis in a head-to-tail orientation with some close contacts of 3.438 $(\mathrm{C} 8 \cdots \mathrm{S} 11)$ and $3.487(\mathrm{C} 2 \cdots \mathrm{S} 12) \AA$ (Figure S3). Within the ac plane, short intermolecular S $\cdots \mathrm{S}$ contacts of $3.389 \AA(\mathrm{S} 2 \cdots \mathrm{S} 5)$ and $\mathrm{N} \cdots \mathrm{S}$ contacts of $3.229 \AA(\mathrm{N} 2 \cdots \mathrm{S} 14)$ occur (Figure S4).

Photophysical properties of TTF-BTD (1): The optical absorption spectrum of $\mathbf{1}$ in a THF solution is shown in Figure 3. In analogy to a similarly fused TTF-BTD compound, ${ }^{[7]}$ the intense absorption bands at $240 \mathrm{~nm}$ and $330 \mathrm{~nm}$ are assigned to electronic $\pi \pi^{*}$ transitions, which are mainly localized on the TTF and BTD moieties. The absorption spectrum in the visible region is clearly dominated by a broad and strong band centered at $495 \mathrm{~nm}$. Based on the computational results from analogous D- $\pi$-A molecules, ${ }^{[13,14]}$ this electronic excitation can unequivocally be characterized as an intramolecular charge-transfer transition (ICT). Essentially, it corresponds to a one-electron excitation from the HOMO localized on the TTF moiety to the LUMO localized on the BTD fragment, hence, an electronic transition which typically occurs within fused D- $\pi$-A molecules. Similar to other TTF fused D-A systems, ${ }^{[13 a]}$ dyad 1 also shows a weak fluorescence with a $\lambda_{\max }$ at $625 \mathrm{~nm}$ and a quantum yield of $1 \%$. The fluorescence excitation spectrum, measured at $630 \mathrm{~nm}$ emission wavelength, matches well with the corresponding absorption profile, hence the emission originates from the ICT state. Furthermore, taking the crossing-point $(560 \mathrm{~nm})$ of the absorption and fluorescence spectra, an optical HOMO-LUMO gap of $2.21 \mathrm{eV}$ is calculated, which indeed matches fairly well with the electrochemical HOMO-LUMO gap of $2.08 \mathrm{eV}$ (see below). Finally, it is worthwhile to note that such a strong optical absorption at relatively low energy is a rare characteristic for small closed-shell molecules; it is clearly the outcome of an electronic interaction due to the compact fusion of donor and acceptor units into a planar $\pi$-conjugated system. 


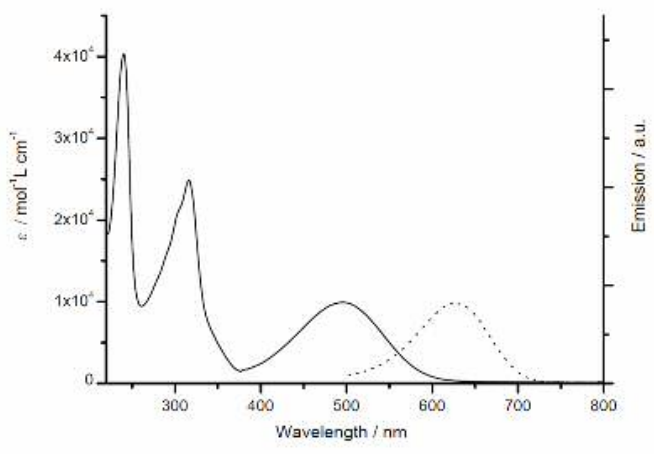

Figure 3. Absorption and emission $\left(\lambda_{\mathrm{ex}}=495 \mathrm{~nm}\right)$ spectra of TTF-BTD (1) in THF at room temperature.

Table 1. Crystallographic data for $\mathbf{1},\left\{(\mathbf{1})_{2} \mathrm{I}_{3}\right\}$ and $\left\{\mathbf{1}_{3}\right\} \cdot 1 / 2 \mathrm{I}_{2}$.

\begin{tabular}{|c|c|c|c|c|}
\hline & $1 \alpha$ & $1 \beta$ & $\left\{(\mathbf{1})_{2} \mathrm{I}_{3}\right\}$ & $\left\{1 I_{3}\right\} \cdot 1 / 2 I_{2}$ \\
\hline Formula & $\mathrm{C}_{10} \mathrm{H}_{4} \mathrm{~N}_{2} \mathrm{~S}_{5}$ & $\mathrm{C}_{10} \mathrm{H}_{4} \mathrm{~N}_{2} \mathrm{~S}_{5}$ & $\mathrm{C}_{20} \mathrm{H}_{8} \mathrm{I}_{3} \mathrm{~N}_{4} \mathrm{~S}_{10}$ & $\mathrm{C}_{10} \mathrm{H}_{4} \mathrm{I}_{4} \mathrm{~N}_{2} \mathrm{~S}_{5}$ \\
\hline $\begin{array}{c}\text { Formula } \\
\text { weight }\end{array}$ & 312.45 & 312.45 & 1005.6 & 820.05 \\
\hline Shape & $\begin{array}{c}\text { Elongated } \\
\text { plates }\end{array}$ & $\begin{array}{c}\text { Elongated } \\
\text { plates }\end{array}$ & $\begin{array}{c}\text { Elongated } \\
\text { plates }\end{array}$ & Blocks \\
\hline $\begin{array}{l}\text { Crystal } \\
\text { system }\end{array}$ & Triclinic & Monoclinic & Monoclinic & Triclinic \\
\hline Space group & $P-1$ & $P 2_{1} / c$ & $C 2 / \mathrm{m}$ & $P-1$ \\
\hline$a(\AA)$ & $7.1606(3)$ & $23.4212(3)$ & $20.6674(4)$ & $8.49883(16)$ \\
\hline$b(\AA)$ & $7.4763(2)$ & $7.30207(10)$ & $9.91920(10)$ & $9.5305(2)$ \\
\hline$c(\AA)$ & $11.8068(4)$ & $13.97552(18)$ & $7.25330(10)$ & $11.5940(3)$ \\
\hline$\alpha\left({ }^{\circ}\right)$ & $97.006(3)$ & 90 & 90 & $94.267(2)$ \\
\hline$\beta\left(^{\circ}\right)$ & $106.131(3)$ & $98.1826(11)$ & $106.926(2)$ & $93.2693(17)$ \\
\hline$\gamma\left({ }^{\circ}\right)$ & $105.061(3)$ & 90 & 90 & $101.7275(3)$ \\
\hline$V\left(\AA^{3}\right)$ & $573.34(4)$ & $2365.81(5)$ & $1422.54(4)$ & $914.43(4)$ \\
\hline$Z$ & 2 & 8 & 2 & 2 \\
\hline$\rho_{\text {calc }}\left(\mathrm{g} / \mathrm{cm}^{3}\right)$ & 1.81 & 1.754 & 2.348 & 2.978 \\
\hline$\mu\left(\mathrm{mm}^{-1}\right)$ & 0.983 & 0.952 & 4.052 & 7.379 \\
\hline $\begin{array}{c}\text { Temperature } \\
\text { (K) }\end{array}$ & $173(2)$ & $253(2)$ & $173(2)$ & $173(2)$ \\
\hline No. Refl. & 2840 & 6385 & 14235 & 27994 \\
\hline $\begin{array}{c}R_{1} ; w R_{2}[I> \\
2 \sigma(I)]\end{array}$ & $\begin{array}{c}0.0228 ; \\
0.0568\end{array}$ & $\begin{array}{c}0.0387 \\
0.0836\end{array}$ & $0.0239 ; 0.057$ & $0.02 ; 0.0476$ \\
\hline
\end{tabular}

Electrochemical properties of TTF-BTD (1): Cyclic voltammetry reveals that dyad $\mathbf{1}$ can be oxidised on its donor site (HOMO localisation) to its radical cation $\left(\mathrm{TTF}^{+\bullet}\right)$ and dication $\left(\mathrm{TTF}^{2+}\right)$ sequentially and reversibly at $0.72 \mathrm{~V}$ and $1.16 \mathrm{~V}(v s \mathrm{Ag} / \mathrm{AgCl})$, respectively, which are comparable with the oxidation potentials $(0.73 \mathrm{~V}$ and $1.08 \mathrm{~V})$ of a dyad where the acceptor dipyrido[3,2$\left.a: 2^{\prime}, 3^{\prime}-c\right]$ phenazine is fused to the TTF donor. ${ }^{[13 a]}$ Moreover, the molecule exhibits one reversible reduction wave at $-1.36 \mathrm{~V}$ corresponding to the reduction of the BTD moiety (LUMO localisation). Consequently, the electrochemical HOMO-LUMO gap is $2.08 \mathrm{eV}$.

Organic field-effect transistor characteristics based on TTFBTD (1): A crystalline thin film of $\mathbf{1}$ was prepared by drop casting a solution of the molecule in 1,2-dichlorobenzene on $\mathrm{Si} / \mathrm{SiO}_{2}$ substrates at $100{ }^{\circ} \mathrm{C}$. Afterwards graphite source and drain electrodes were painted on top of the crystal (Figure S5). The OFET characteristics of these films in bottom-gate top-contact architecture are illustrated in Figure 4. This material shows typical electrical $p$ channel characteristics. A very small hysteresis was observed between forward and reverse VD sweeps. Furthermore, a low threshold voltage of about $V_{\mathrm{TH}}=-3.3 \mathrm{~V}$ was extracted in the saturation regime, indicating a low level of unintentional doping of the active material. From the saturation regime a field-effect mobility of $\mu_{\mathrm{FE}}=(1.3 \pm 0.5) \times 10^{-3} \mathrm{~cm}^{2} / \mathrm{Vs}$ was extracted. A set of 4 devices was measured under ambient conditions and darkness, exhibiting similar values in terms of device performance. Additionally, thin film transistors were fabricated by thermal evaporation of the organic material in a bottom-gate bottom-contact configuration on both $\mathrm{Si} / \mathrm{SiO}_{2}$ and $\mathrm{Si} / \mathrm{SiO}_{2} / \mathrm{OTS}$ substrates (OTS stands for octadecyltrichlorosilane, Figure S6). The field-effect mobility extracted in the saturation regime was found to be $\mu_{\mathrm{FE}}=$ $(1.4 \pm 0.2) \times 10^{-3} \mathrm{~cm}^{2} / \mathrm{Vs}$ and $\mu_{\mathrm{FE}}=(2.7 \pm 0.4) \times 10^{-3} \mathrm{~cm}^{2} / \mathrm{Vs}$ for devices based on bare $\mathrm{SiO}_{2}$ and OTS-treated substrates, respectively. Both device types exhibited slightly negative threshold voltages when measured as prepared under vacuum and darkness. Interestingly, the devices based on OTS treated $\mathrm{SiO}_{2}$ showed higher stability under ambient conditions reflected in a less pronounced shift of the threshold voltage to more positive values. The field effect mobility did not exhibit a significant change when the devices were exposed to ambient conditions for ten days (Figures S7, S8 and Table S1). Both solution grown and thermally evaporated thin films of TTF-BTD (1) were characterized by powder X-ray diffraction (Figure S9). The reflections observed in both cases do not coincide with any of the two polymorphs of TTF-BTD (1) resolved and previously mentioned. The reflections from the solution grown films do not coincide with those of the thermally evaporated thin films either. This result indicates the formation of two new polymorphs when the material is crystallised on surface, an effect commonly found in organic semiconductors, including TTFs. ${ }^{[15]}$ 


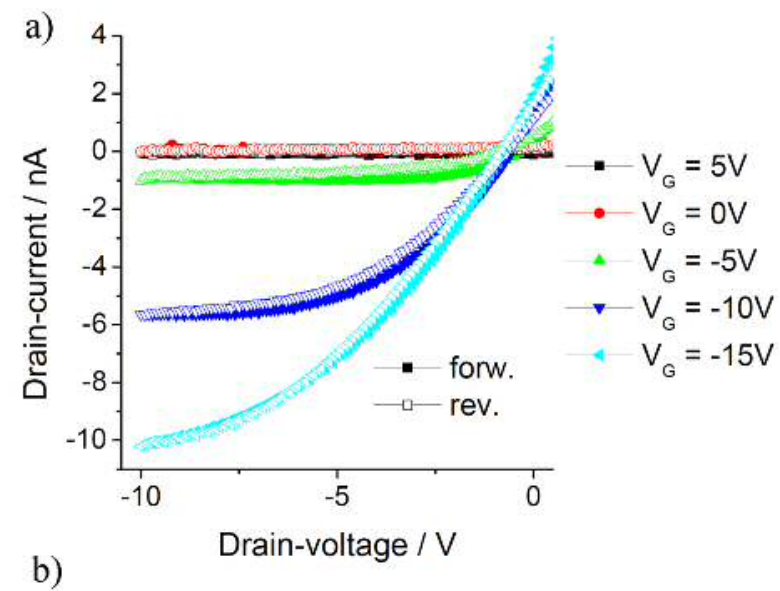

b)

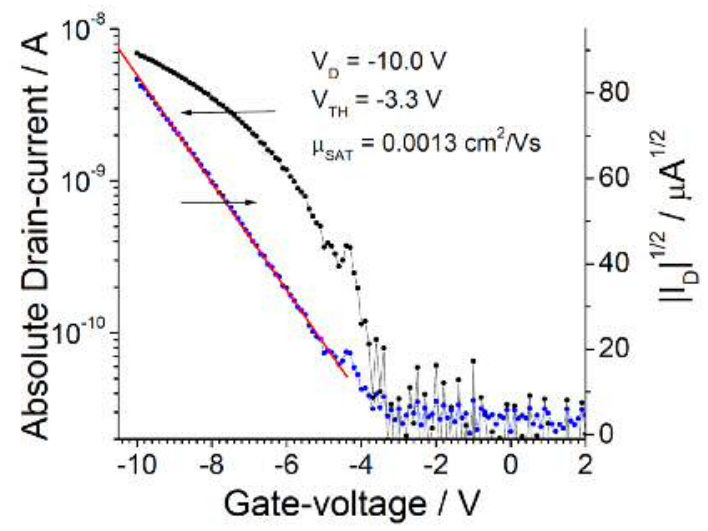

Figure 4. Electrical characterization of a solution grown crystalline film of TTF-BTD (1). Output characteristics (top) and corresponding transfer characteristics (bottom) in the saturation regime with extraction of field-effect mobility and threshold voltage.

Crystal structure of the CT salt $\left\{(\mathbf{1})_{2} \mathbf{I}_{3}\right\}$ : Controlled chemical oxidation by slow diffusion of $\mathrm{I}_{2}$ in a solution of TTF-BTD (1) induces the crystallisation of the CT salt $\left\{(\mathbf{1})_{2} \mathrm{I}_{3}\right\}$ as black shiny elongated plate-like crystals. This salt crystallises in the monoclinic space group $C 2 / \mathrm{m}$ (Table 1 ). The partially oxidised TTF-BTD molecule lies across a crystallographic mirror plane and thus only half of the molecule comprises the asymmetric part of the unit cell (S1, C4 and C5 lie on special positions with Wyckoff letter i); consequently, there is only one crystallographically unique TTFBTD molecule in the crystal structure, and therefore it bears a positive charge of +0.5 . Similarly, the $\mathrm{I}_{3}^{-}$anion lies on special positions with Wyckoff letters $d$ and $i$ for I1 and I2, respectively. Figure 5 shows an ORTEP view with the labeling scheme of the partially oxidised (TTF-BTD) ${ }^{+0.5}$ and $\mathrm{I}_{3}^{-}$. The skeleton of the molecule shows a nearly planar geometry, apart from a slight bending at the BTD site; the rms deviation from a least-squares plane through all the atoms is $0.1138 \AA$ and a least-squares plane through the atoms of the TTF core alone reveals a rms deviation of only $0.0452 \AA$.
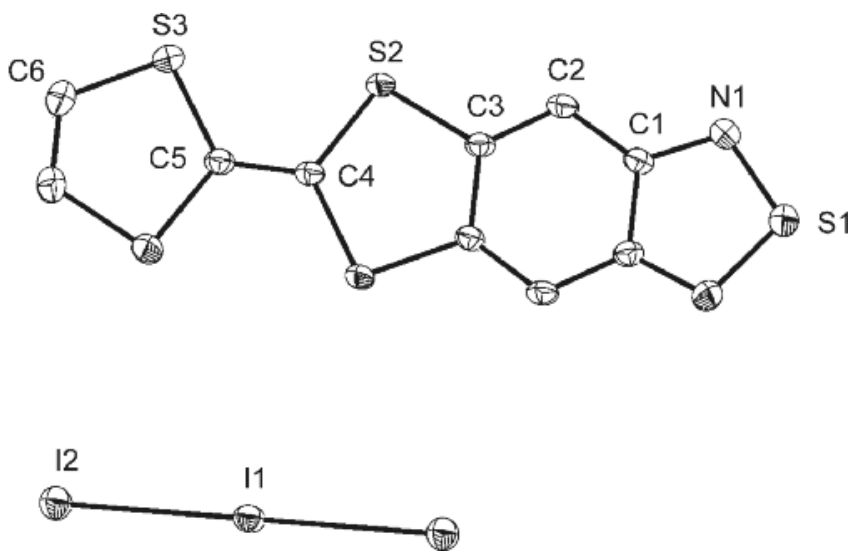

Figure 5. ORTEP drawing and atomic numbering scheme of (TTF-BTD) ${ }^{+0.5}$ and $\mathrm{I}_{3}{ }^{-}$of $\left\{(\mathbf{1})_{2} \mathrm{I}_{3}\right\}$. Ellipsoids are set at $50 \%$ probability; hydrogen atoms have been omitted for clarity.

A significant aspect of the crystal structure of $\left\{(\mathbf{1})_{2} \mathrm{I}_{3}\right\}$ is the stacking model of the partially oxidised TTF-BTD molecules. As illustrated in Figure 6, these stacks extend along the crystallographic c axis without offset to the side (molecular short axis) within the columnar $\pi$-stack, which leads to a partial ring-over-bond type arrangement (Figures S10 and S11). In addition, the D-A character of each molecule creates a significant dipole, causing adjacent molecules to align in a head-to-tail manner in order to cancel the dipole in the solid. The separations along the $\pi$-stack between adjacent coplanar least-squares planes through the TTF cores show alternating values of $3.463 \AA$ and $3.623 \AA$. Similarly, the four short $\mathrm{S} \cdots \mathrm{S}$ distances between adjacent TTFs within a stack are alternatingly $3.529 \AA$ and $3.728 \AA$; these values are close to the van der Waals distance $(3.60 \AA)$ of sulfur.
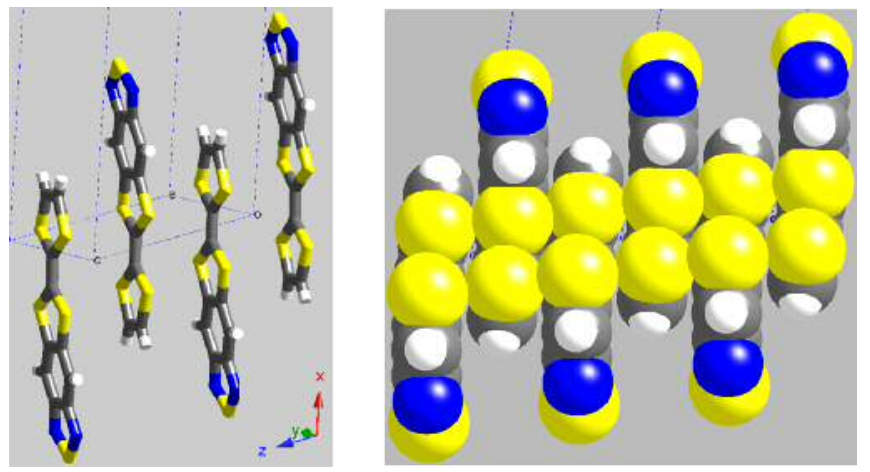

Figure 6. (Left) View of the (TTF-BTD $)^{+0.5}$ head-to-tail packing along the $c$ axis for $\left\{(\mathbf{1})_{2} \mathrm{I}_{3}\right\}$; (Right) analogous space filling representation of the $\pi$-stack, viewed down the $b$ axis.

A projection of the structure along the (TTF-BTD) ${ }^{+0.5}$ stacking direction highlights a two-dimensional regular pattern of the molecules. Figure 7 shows a fragment of such an array in the $a b$ plane and illustrates that the D-A polarity arrows for all molecules point in the same direction within a layer; this orientation changes by $180^{\circ}$ from layer to layer. Close $\mathrm{N} \cdots \mathrm{S}$ contacts $(3.203 \AA)$ from heads to tails among neighbouring molecules occur. This packing arrangement results in separated stacks of the molecules, whereby the large cavities between them are occupied by linear $\mathrm{I}_{3}{ }^{-}$anions. Their terminal iodine atoms establish four short contacts $(3.082 \AA)$ to the $\mathrm{H}$-atoms of the benzene units which are situated in two 
neighbouring layers, whereas the distances to two next positioned S1 atoms from BTD moieties amount to $3.632 \AA$. A crude approach can relate these values to the relevant van der Waals distances 3.18 $\AA(\mathrm{H} \cdots \mathrm{I})$ and $3.72 \AA(\mathrm{S} \cdots \mathrm{I})$.

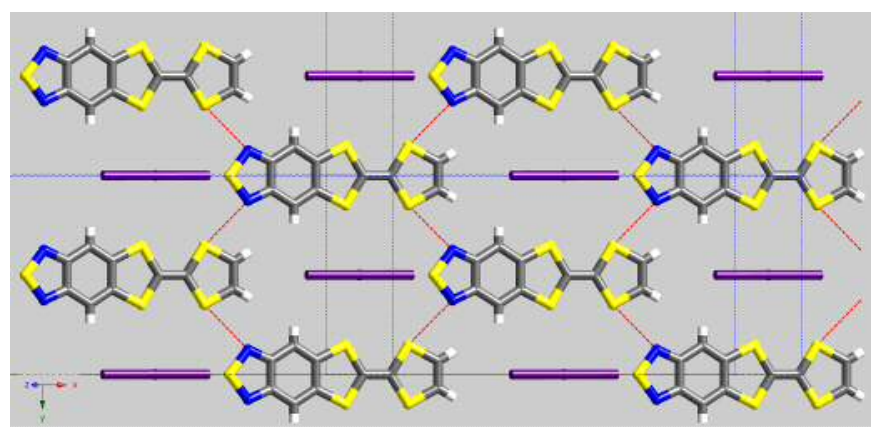

Figure 7. Projection approximately down the $c$ axis of the structure of $\left\{(\mathbf{1})_{2} \mathrm{I}_{3}\right\}$. The dashed lines show short $\mathrm{N} \cdots \mathrm{S}$ contacts among neighbouring molecules $(3.203 \AA)$.

Conductivity properties of $\left\{(\mathbf{1})_{2} \mathbf{I}_{\mathbf{3}}\right\}$ : Resistivity measurements performed from $310 \mathrm{~K}$ down to $\sim 100 \mathrm{~K}$ have shown that single crystals of the CT salt $\left\{(\mathbf{1})_{2} \mathrm{I}_{3}\right\}$ reveal semiconductor-like behaviour with a room temperature conductivity of ca. $2 \mathrm{~S} \mathrm{~cm}^{-1}$. Notably, the activation energy is not constant for the region from room temperature to $100 \mathrm{~K}$ and lies in the range of 150 to $100 \mathrm{meV}$ (Figure 8).

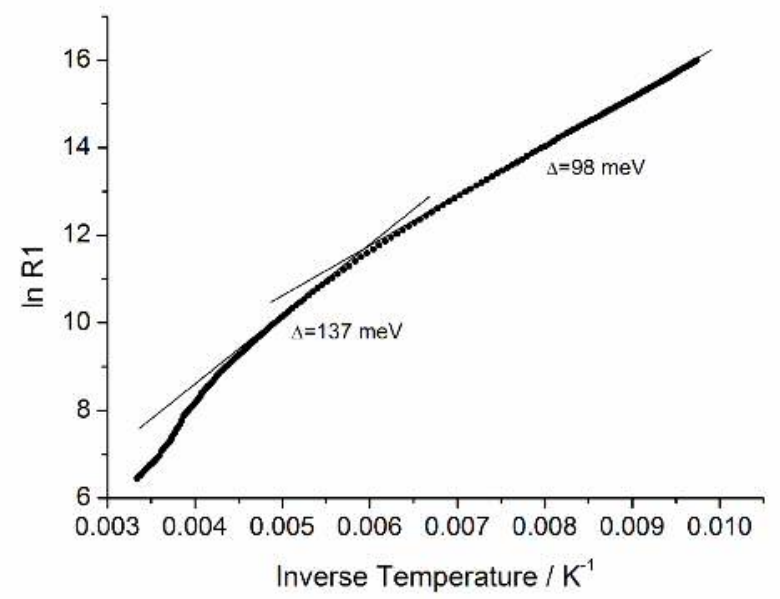

Figure 8. Electrical resistivity of a single crystal of $\left\{(\mathbf{1})_{2} \mathrm{I}_{3}\right\}$ as a function of the reciprocal temperature.

Crystallisation and crystal structure of the CT salt $\left\{1 \mathrm{I}_{3}\right\} \cdot 1 / 2 \mathbf{I}_{2}$ : The oxidation and crystallisation process which leads to the partially oxidised crystalline CT salt with the formula $\left\{(\mathbf{1})_{2} \mathrm{I}_{3}\right\}$ does eventually, after a longer time period (see Experimental section) also result in the formation of a few prismatically shaped black crystals of formula $\left\{\mathbf{1 I}_{3}\right\} \cdot 1 / 2 \mathrm{I}_{2}$. This compound, where the TTF-BTD molecule is now fully oxidised, crystallises in the triclinic space group $P-1$ (Table 1). The asymmetric unit comprises the (TTFBTD $)^{+1}$ cation and the $\mathrm{I}_{3}{ }^{-}$anion whose atoms lie on general positions, and only the $\mathrm{I}_{2}$ molecule lies on a special position with an inversion center. An ORTEP drawing of (TTF-BTD) ${ }^{+1}$ is shown in Figure S12. The skeleton of the fully charged molecule shows a nearly planar geometry; the rms deviation from a least-squares plane through all the atoms is $0.0608 \AA$ and a least-squares plane through the atoms of the TTF core alone reveals a rms deviation of only $0.0358 \AA$. The crystal packing is shown in Figure S13. In contrast to the partially oxidised CT salt, the crystal structure of the fully oxidised compound shows no extended $\pi$-stacks; the (TTF-BTD) ${ }^{+1}$ cations are arranged as isolated dimers in a head-to-tail manner with some close $\mathrm{S} \cdots \mathrm{S}$ contacts of $3.306 \AA(\mathrm{S} 3 \cdots \mathrm{S} 4)$ and $3.336(\mathrm{~S} 2 \cdots \mathrm{S} 5) \AA$.

As well established for $\mathrm{CT}$ salts, the partial charge residing on a TTF moiety can be estimated using the bond lengths of the central $\mathrm{C}=\mathrm{C}$ bond and the $\mathrm{C}-\mathrm{S}$ bonds of the dithiole ring (labelled as $a \cdots d$ in Figure 2, Table 2). These distances depend most sensitively on the oxidation state of the TTF moiety in the donor molecule. ${ }^{[16]}$ For instance, the average bond length of the central $\mathrm{C}=\mathrm{C}$ bond is $1.32 \AA$ in the neutral state and $1.38 \AA$ in the fully oxidised state with a charge of $+1 .{ }^{[17-19]}$ Although in the case of $\left\{(\mathbf{1})_{2} \mathrm{I}_{3}\right\}$, it can directly be inferred from the stoichiometry of the compound and from the fact that there is only one crystallographically unique TTF-BTD molecule in the crystal structure, that each TTF-BTD molecule has the formal charge of +0.5 , nevertheless it is valuable to account for the occurring bond length variations. Table 2 lists some relevant distances and these values confirm the expectation. The central $\mathrm{C}=\mathrm{C}$ bond length of 1.399(3) $\AA$ for the TTF unit in $\left\{\mathbf{1 I}_{3}\right\} \cdot 1 / 2 \mathrm{I}_{2}$ confirms its fully oxidized state. However, it is also noticeable that the annulation of an acceptor unit to the TTF skeleton leads per se to a systematic lengthening of the central $\mathrm{C}=\mathrm{C}$ bond. ${ }^{[13,14]}$

Table 2. Interatomic distances $(\AA)^{[\mathrm{a}]}$ of TTF-BTD (1) and its CT salts $\left\{(\mathbf{1})_{2} \mathrm{I}_{3}\right\}$ and $\left\{\mathbf{1}_{3}\right\} \cdot 1 / 2 \mathrm{I}_{2}$ for comparison.

\begin{tabular}{|c|c|c|c|c|c|}
\hline & \multirow{2}{*}{$\begin{array}{c}1 \alpha(\text { space } \\
\text { group } P-1)\end{array}$} & \multicolumn{2}{|c|}{$\mathbf{1} \beta$ (space group $P 2_{1} / c$ ) } & \multirow[t]{2}{*}{$(\mathbf{1})_{2} \mathrm{I}_{3}$} & $\multirow[t]{2}{*}{\mathrm{II}_{3}} \cdot 1 / 2 \mathrm{I}_{2}$ \\
\hline & & $\begin{array}{c}\text { Molecule } \\
\text { A }\end{array}$ & $\begin{array}{c}\text { Molecule } \\
\text { B }\end{array}$ & & \\
\hline$a$ & $1.3459(18)$ & $1.341(3)$ & $1.338(3)$ & $1.364(5)$ & $1.399(3)$ \\
\hline$\left(b+b^{\prime}\right) / 2$ & 1.7557 & 1.754 & 1.757 & $1.7405(19)$ & 1.720 \\
\hline$\left(c+c^{\prime}\right) / 2$ & 1.7398 & 1.736 & 1.732 & $1.728(3)$ & 1.719 \\
\hline$d$ & $1.321(2)$ & $1.320(4)$ & $1.324(4)$ & $1.339(5)$ & $1.344(4)$ \\
\hline
\end{tabular}

[a] Labels $a \ldots d$ refer to Figure 2.

\section{Conclusion}

This experimental study about the compact tetrathiafulvalenebenzothiadiazole (TTF-BTD) dyad $\mathbf{1}$ makes a number of valid points. In contrast to most of the reported fused donor-acceptor systems, compound $\mathbf{1}$ bears no substituents, a fact which will mainly influence its solid state assembly in a favourable manner with respect to thin film formation, a process which is relevant for OFET applications leading to a field-effect mobility of up to $2.7 \times 10^{-3}$ $\mathrm{cm}^{2} / \mathrm{Vs}$ for this dyad. Furthermore, beneficial to the occurrence of intense optical absorptions at relatively low energy is the specific type of molecular structure, as given through the compact fusion of the donor and acceptor units into a $\pi$-conjugated skeleton which thereby leads to a low-lying ICT state. In addition, the redox activity of 1 leads to the crystallisation of a unique charge-transfer salt with formula $\left\{(\mathbf{1})_{2} \mathrm{I}_{3}\right\}$, which due to its simple and compact molecular 
moiety (no substituents, see above) exhibits a highly symmetrical crystal structure. Single crystals of this semiconducting CT salt show a room temperature electrical conductivity of the order of $2 \mathrm{~S}$ $\mathrm{cm}^{-1}$. Most interestingly, this CT salt now represents a case in which the regular $\pi$-stacks of $\mathrm{TTF}^{+0.5}$ are closely bonded to the BTD acceptors (bonded along the ridge), which represent the LUMO localisation. A detailed theoretical investigation of this specific electronic structure is the scope of a further study. Finally, a fully oxidised CT salt of stoichiometry $\left\{\mathbf{1 I}_{3}\right\} \cdot 1 / 2 \mathrm{I}_{2}$ could be verified by a single crystal structure determination.

\section{Experimental Section}

General: Air and/or water-sensitive reactions were conducted under Ar in dry, freshly distilled solvents. Elemental analyses were performed on an EA 1110 Elemental Analyzer CHN Carlo Erba Instruments. ${ }^{1} \mathrm{H}$ NMR spectra were recorded on a Bruker Avance $300(300 \mathrm{MHz})$ spectrometer. Chemical shifts are reported in parts per million (ppm) and are referenced to the residual solvent peak (chloroform, ${ }^{1} \mathrm{H}=7.26 \mathrm{ppm},{ }^{13} \mathrm{C}=$ $77.0 \mathrm{ppm}$; DMSO, ${ }^{1} \mathrm{H}=2.50 \mathrm{ppm},{ }^{13} \mathrm{C}=39.6 \mathrm{ppm}$ ). Peak multiplicities are described in the following way: singlet (s). FT-IR spectra were recorded on a Perkin-Elmer One FT IR spectrometer. HRMS data was obtained with ESI (electrospray ionization) mode on LTQ Orbitrap XL. Photophysical measurements were performed on degassed solutions of 1 dissolved in THF. The absorption spectrum was recorded on a Cary $5000 \mathrm{UV} / \mathrm{Vis}$ spectrophotometer. Emission and excitation spectra were measured on a Horiba Fluorolog 3. The luminescence quantum yield $\Phi_{\mathrm{F}}$ of $\mathbf{1}$ was determined by relative measurements ${ }^{[20]}$ with respect to the standard value of a solution of Rhodamin $6 \mathrm{G}$ in $\mathrm{EtOH}\left(\Phi_{\mathrm{F}}=95 \%\right)$ at the excitation wavelength $480 \mathrm{~nm} \cdot{ }^{[21]}$ Atomic Force Microscopy (AFM) images were taken with a 5500LS SPM system from Agilent Technologies under ambient conditions. Powder X-ray diffraction (PXRD) measurements for both thermally evaporated thin films and solution grown crystalline films were performed using a modular X-ray powder diffractometer RIGAKU.

Materials: Unless otherwise stated, all reagents were purchased from commercial sources and used without additional purification. [1,3]Dithiolo[4,5- $f]-2,1,3$ benzothiadiazole-6-thione (2), ${ }^{[13 a]}$ was prepared according to the literature procedure.

Synthesis of $[\mathbf{1 , 3}]$ dithiolo[4,5- $f]$-2,1,3-benzothiadiazole-6-one (3): $\mathrm{Hg}(\mathrm{OAc})_{2}(480 \mathrm{mg}$, $1.5 \mathrm{mmol})$ was added to a solution of $2(120 \mathrm{mg}, 0.5 \mathrm{mmol})$ in dichloromethane (10 $\mathrm{mL}$ ). The mixture was stirred at room temperature for $30 \mathrm{~min}$. The light yellow solid was filtered off and the filtrate was collected and evaporated by rotavapor to afford $\mathbf{3}$ as a pale-yellow powder. Yield: $102 \mathrm{mg}(91 \%)$; m.p.: $192-193^{\circ} \mathrm{C}$; IR $(\mathrm{KBr}): v=3436$ 2919, 1648, 1423, 1242, 1074, 879, 854, 844, $821 \mathrm{~cm}^{-1} ;{ }^{1} \mathrm{H}$ NMR $\left(300 \mathrm{MHz}, \mathrm{CDCl}_{3}\right): \delta$ $=8.18(\mathrm{~s}) ;{ }^{13} \mathrm{C}$ NMR $\left(300 \mathrm{MHz}, \mathrm{CDCl}_{3}\right): \delta=188.0,152.9,136.7,114.9$; elemental analysis calcd (\%) for $\mathrm{C}_{7} \mathrm{H}_{2} \mathrm{~N}_{2} \mathrm{OS}_{3}$ : C $37.15, \mathrm{H} 0.89, \mathrm{~N} 12.38$; found: $\mathrm{C} 37.32, \mathrm{H} 0.88, \mathrm{~N}$ 12.16

Synthesis of 2-(1,3-dithiol-2-ylidene)-[1,3]dithiolo[4,5-f $f$-2,1,3-benzothiadiazole (1): Triethyl phosphite $(4 \mathrm{~mL})$ was added to a mixture of $\mathbf{3}(79 \mathrm{mg}, 0.35 \mathrm{mmol})$ an vinylene trithiocarbonate $(117 \mathrm{mg}, 0.875 \mathrm{mmol})$ in toluene $(2 \mathrm{~mL})$ under Ar. The resulting solution was refluxed for $3 \mathrm{~h}$. After cooling to room temperature, the crude product was collected by filtration, washed with $\mathrm{MeOH}$ and then purified by column chromatography on silica gel using a mixture of hexane and dichloromethane (2:1) as eluent to afford 1 as a deep red powder. Yield: $51 \mathrm{mg}(47 \%)$; m.p.: $246-247^{\circ} \mathrm{C}$; IR $(\mathrm{KBr}): v=3437,2918,1635,1477,1426,1386,1242,1076,841,812,800,634 \mathrm{~cm}^{-1}$, ${ }^{1} \mathrm{H}$ NMR $\left(300 \mathrm{MHz}\right.$, DMSO- $\left.d_{6}\right): \delta=8.24(\mathrm{~s}), 6.83(\mathrm{~s}) ;{ }^{13} \mathrm{C}$ NMR $\left(300 \mathrm{MHz}\right.$, DMSO- $\left.d_{6}\right):$ $\delta=152.9,142.1,119.8,119.5,112.3,102.9$; HRMS (ESI): $m / z$ calcd for $\mathrm{C}_{10} \mathrm{H}_{4} \mathrm{~N}_{2} \mathrm{~S}_{5}$ 311.8978; found: 311.8965 .

Crystallisation of $\left\{(\mathbf{1})_{2} \mathbf{I}_{3}\right\}$ and $\left\{\mathbf{1}_{3}\right\} \cdot 1 / 2 \mathbf{I}_{2}$ : In a typical experiment, $\mathrm{I}_{2}(0.02 \mathrm{mmol})$ in $\mathrm{MeOH}(5 \mathrm{~mL})$ was layered over a solution of $\mathbf{1}(0.01 \mathrm{mmol})$ in dichloromethane $(5 \mathrm{~mL})$. Black, elongated plate-like crystals of formula $\left\{\left(\mathbf{1}_{2} \mathrm{I}_{3}\right\}\right.$ were formed during two weeks. Yield: $3.1 \mathrm{mg}(61.0 \%)$; IR (KBr): $v=3437,2918,1635,1489,1426,1386,1336,1242$, $1076,869,812,800,647,462,448 \mathrm{~cm}^{-1}$; elemental analysis calcd (\%) for $\mathrm{C}_{20} \mathrm{H}_{8} \mathrm{I}_{3} \mathrm{~N}_{4} \mathrm{~S}_{10}$ C 23.89, H 0.80, N 5.57; found: C 23.67, H 0.74, N 5.13. After filtering off the crystal and keeping the solution for slow evaporation for another couple of days, some few black prismatic single crystals appeared. A single crystal X-ray diffraction measurement revealed the stoichiometry as $\left\{1 \mathrm{I}_{3}\right\} \cdot 1 / 2 \mathrm{I}_{2}$

X-Ray structure determination: Suitable single crystals of $1,\left\{(1)_{2} \mathrm{I}_{3}\right\}$ and $\left\{1 \mathrm{I}_{3}\right\} \cdot 1 / 2 \mathrm{I}_{2}$ were selected and mounted with Paratone on a glass needle and used for X-ray structure determination at $253 \mathrm{~K}$ and $173 \mathrm{~K}$, respectively. All measurements were made on a Oxford Diffraction SuperNova area-detector diffractometer ${ }^{[22]}$ using mirror optics monochromated Mo K $\alpha$ radiation $(\lambda=0.71073 \AA)$. Data reduction was performed using the CrysAlisPro ${ }^{[22]}$ program. The intensities were corrected for Lorentz and polarization effects, and an absorption correction based on the multi-scan method using SCALE3 ABSPACK in CrysAlisPro ${ }^{[22]}$ was applied. The structure was solved by direct methods using SIR97, ${ }^{[23]}$ which revealed the positions of all non-hydrogen atoms. The nonhydrogen atoms were refined anisotropically. All H-atoms were placed in geometrically calculated positions and refined using a riding model where each $\mathrm{H}$-atom was assigned a fixed isotropic displacement parameter with a value equal to $1.2 \mathrm{Ueq}$ of its parent atom. Refinement of the structure was carried out on $F^{2}$ using full-matrix least-squares procedures, which minimized the function $\Sigma w\left(F_{0}^{2}-F_{c}^{2}\right)^{2}$. The weighting scheme was based on counting statistics and included a factor to downweight the intense reflections. All calculations were performed using the SHELXL-97 program. ${ }^{[2]}$ Crystal data, data collection and refinement parameters for $1,\left\{(1)_{2} \mathrm{I}_{3}\right\}$ and $\left\{\mathbf{1}_{3}\right\} \cdot 1 / 2 \mathrm{I}_{2}$ are given in Table 1 .

Cyclic voltammetry (CV): CV was performed in a three-electrode cell equipped with a Pt-disk working electrode and a glassy carbon counter-electrode; $\mathrm{Ag} / \mathrm{AgCl}$ containing $2 \mathrm{M} \mathrm{LiCl}$ (in ethanol) was used as the reference electrode. The electrochemical experiments were carried out at room temperature under Argon in dichloromethane $(\mathrm{DCM})$ with $\mathrm{Bu}_{4} \mathrm{~N}\left(\mathrm{PF}_{6}\right)(0.1 \mathrm{M})$ as a supporting electrolyte. The voltammograms were recorded on a PGSTAT 101 potentiostat.

Conductivity measurements: Resistivity measurements were performed for elongated plate-like crystals of $\left\{(1)_{2} \mathrm{I}_{3}\right\}$ with typical sizes of $2 \times 0.2 \times 0.04 \mathrm{~mm}^{3}$ using a standard four-probe $d c$-method from $310 \mathrm{~K}$ down to $\sim 100 \mathrm{~K}$. Four annealed platinum wires (20 $\mu \mathrm{m}$ in diameter) were attached to the crystals by a conductive graphite paste. All four contacts were placed on the same elongated conducting surface (in $b c$-plane or perpendicular to the $a^{*}$ axis).

Preparation of solution processed crystalline film OFETs: $\mathrm{Bare} \mathrm{Si} / \mathrm{SiO}_{2}$ wafer pieces (purchased at Si-Mat) were used as a substrate for the solution grown crystalline films. Highly $n$-doped silicon was used as a common gate electrode. The thickness of the dielectric layer was about $50 \mathrm{~nm}$. TTF-BTD was dissolved in 1,2-dichlorobenzene with a concentration of $c=1 \mathrm{mg} / \mathrm{ml}$ at T $=100{ }^{\circ} \mathrm{C}$. Silicon substrates were stored within an oven at $\mathrm{T}=100{ }^{\circ} \mathrm{C}$ before drop-casting the hot solution and covered with a Petri dish to slow down the evaporation process. After complete evaporation of the solvent, the samples were slowly cooled down to room temperature to prevent stress in the crystalline films. Source and drain electrodes were fabricated with graphite paste (Dotite XC-12). After drying the graphite paste for $1 \mathrm{~h}$ at ambient conditions, the electrical characterization was carried out with a Keithley 2612A Source Meter under ambient conditions and darkness. Channel length and width $(W=640 \pm 100 \mu \mathrm{m}, L=$ $180 \pm 50 \mu \mathrm{m})$ were measured with an Olympus BX51 optical microscope.

Preparation of thermally evaporated thin film OFETs: $\mathrm{Si} / \mathrm{SiO}_{2}$ wafer pieces with ITO/Au as source and drain interdigitated electrodes $(W=10 \mathrm{~mm}, L=20,10,5 \mu \mathrm{m})$ in a bottom-gate bottom-contact geometry (purchased at Fraunhofer, IPMS) were used as a substrate. Highly $n$-doped silicon was used as a common gate electrode. The thickness of the dielectric layer was about $230 \mathrm{~nm}$. TTF-BTD was thermally evaporated at $\mathrm{T}=$ $115-150{ }^{\circ} \mathrm{C}$ and $\mathrm{P}=2 \times 10^{-6} \mathrm{mbar}$ with an evaporation rate of about $0.5 \AA / \mathrm{s}$. Two different device types were prepared, where in the first case TTF-BTD was directly evaporated on bare $\mathrm{SiO}_{2}$, while in the second case an OTS (octadecyltrichlorosilane) monolayer was applied to the $\mathrm{SiO}_{2}$ before the deposition of the active material. After the deposition of TTF-BTD, the samples were transferred to the electrical characterization system as quickly as possible to reduce exposure to ambient conditions. The measurement system was equipped with micromanipulators for easy connection in a vacuum chamber (P 50 mbar). The electrical characterization was done with a HewlettPackard semiconductor parameter analyzer 4156A under darkness.

With the aim to obtain information regarding ambient stability of the thermally evaporated films, the devices were measured with a Keithley 2612A Source Meter and home made routines for device control under environmental conditions, after storage under ambient conditions and darkness $(\mathrm{RH}=40-60 \%)$ of up to ten days. The fieldeffect mobility and the threshold voltage were extracted in the saturation regime using the relation ${ }^{[25]}$

$$
\mu_{\mathrm{SAT}}=\frac{2 L}{W C_{\mathrm{i}}}\left(\frac{\partial \sqrt{I_{\mathrm{SD} . \mathrm{SAT}}}}{\partial V_{\mathrm{SG}}}\right)^{2}
$$

\section{Acknowledgements}

Financial support for this research by the Swiss National Science Foundation (Grant No. 200021-147143), ERC StG 2012-306826 e-GAMES, the Networking Research Center on Bioengineering, Biomaterials and Nanomedicine (CIBER-BBN) and the DGI (Spain) with project POMAS CTQ2010-19501/BQU as well as TEC2011-27859-C0201 is gratefully acknowledged.

[1] a) TTF Chemistry: Fundamentals and Applications of Tetrathiafulvalene, (Eds: J. Yamada, T. Sugimoto), Springer Verlag, Berlin, 2004; b) Organic Superconductors (including Fullerenes), (Eds: J. M. Williams, J. R. Ferraro, R. J. Thorn, K. D. Carlson, U. Geiser, H. H. Wang, A. M. Kini, M.-H. Whangbo), Prentice Hall, Englewod Cliffs, 1992.

[2] J. L. Segura, N. Martín, Angew. Chem. Int. Ed. 2001, 40, 1372; Angew. Chem. 2001, 113, 1416.

[3] D. Canevet, M. Sallé, G. Zhang, D. Zhang, D. Zhu, Chem. Commun. 2009, 2245.

[4] M. Bendikov, F. Wudl, D. F. Perepichka, Chem. Rev. 2004, 104, 4891.

[5] M. Mas-Torrent, C. Rovira, J. Mater. Chem. 2006, 16, 433. 
[6] a) Y. Wu, W. Zhu, Chem. Soc. Rev. 2013, 42, 2039; (b) C. R. Belton, A. L. Kanibolotsky, J. Kirkpatrick, C. Orofino, S. E. T. Elmasly, P. N. Stavrinou, P. J. Skabara, D. D. C. Bradley, Adv. Funct. Mater. 2013, 23, 2792; (c) L. V. Brownell, K. Jang, K. A. Robins, I. C. Tran, C. Heske, D.-C. Lee, Phys. Chem. Chem. Phys. 2013, 15, 5967; (d) M. Scarongella, A. Laktionov, U. Röhtlisberger, N. Banerji, J. Mater. Chem. C 2013, 1, 2308; (e) G. Yang, C.-A. Di, G. Zhang, J. Zhang, J. Xiang, D. Zhang, D. Zhu, Adv. Funct. Mater. 2013, 23, 1671.

[7] a) F. Pop, A. Amacher, N. Avarvari, J. Ding, L. M. L. Daku, A. Hauser, M Koch, J. Hauser, S.-X. Liu, S. Decurtins, Chem. Eur. J. 2013, 19, 2504; b) A. Amacher, H. Luo, Z. Liu, M. Bircher, M. Cascella, J. Hauser, S. Decurtins, D Zhang, S.-X. Liu, RSC Adv. 2014, 4, 2873.

[8] M. Mas-Torrent, C. Rovira, Chem. Soc. Rev. 2008, 37, 827.

[9] a) M. M. Payne, S. R. Parkin, J. E. Anthony, C.-C. Kuo, T. N. Jackson, J. Am Chem. Soc. 2005, 127, 4986; b) T. Izawa, E. Miyazaki, K. Takimiya, Adv. Mater 2008, 20, 3388; c) H. Ebata, T. Izawa, E. Miyazaki, K. Takimiya, M. Ikeda, H. Kuwabara, T. Yui, J. Am. Chem. Soc. 2007, 129, 15732; d) T. Kadoya, M. Ashizawa, T. Higashino, T. Kawamoto, S. Kumeta, H. Matsumoto, T. Mori, Phys. Chem. Chem. Phys. 2013, 15, 17818 .

[10] a) M. Mas-Torrent, M. Durkut, P. Hadley, X. Ribas, C. Rovira, J. Am. Chem. Soc. 2004, 126, 984; b) Y. Takahashi, T. Hasegawa, S. Horiuchi, R. Kumai, Y. Tokura, G. Saito, Chem. Mater. 2007, 19, 6382; c) Naraso, J. Nishida, D. Kumaki, S. Tokito, Y. Yamashita, J. Am. Chem. Soc. 2006, 128, 9598; d) X. K Gao, Y. Wang, X. D. Yang, Y. Q. Liu, W. F. Qiu, W. P. Wu, H. J. Zhang, T. Qi, Y. Liu, K. Lu, C. Y. Du, Z. G. Shuai, G. Yu, D. B. Zhu, Adv. Mater. 2007, 19 3037

[11] a) F. Otón, R. Pfattner, E. Pavlica, Y. Olivier, G. Bratina, J. Cornil, J. Puigdollers, R. Alcubilla, X. Fontrodona, M. Mas-Torrent, J. Veciana, C. Rovira, CrystEngComm. 2011, 13, 6597; b) R. Pfattner, E. Pavlica, M. Jaggi, S.-X. Liu, S. Decurtins, G. Bratina, J. Veciana, M. Mas-Torrent, C. Rovira, J. Mater. Chem. $C, \mathbf{2 0 1 3}, 1,3985$.

[12] a) X. Shao, Y. Yoshida, Y. Nakano, H. Yamochi, M. Sakata, M. Maesato, A. Otsuka, G. Saito, S. Koshihara, Chem. Mater. 2009, 2l, 1085; b) E. Coronado, S. Curreli, C. Giménez-Saiz, C. J. Gomez-Garcia, P. Deplano, M. L. Mercuri, A. Serpe, L. Pilia, C. Faulmann, E. Canadell, Inorg. Chem. 2007, 46, 4446.

[13] a) C.-Y. Jia, S.-X. Liu, C. Tanner, C. Leiggener, A. Neels, L. Sanguinet, E. Levillain, S. Leutwyler, A. Hauser, S. Decurtins, Chem. Eur. J. 2007, 13, 3804; b) C.-Y. Jia, S.-X. Liu, C. Tanner, C. Leiggener, L. Sanguinet, E. Levillain, S. Leutwyler, A. Hauser, S. Decurtins, Chem. Commun. 2006, 1878; c) H.-P. Jia, S.-X. Liu, L. Sanguinet, E. Levillain, S. Decurtins, J. Org. Chem. 2009, 74, 5727; d) C. Goze, N. Dupont, E. Beitler, C. Leiggener, H.-P. Jia, P. Monbaron, S.-X. Liu, A. Neels, A. Hauser, S. Decurtins, Inorg. Chem. 2008, 47, 11010; e)
F. Dumur, N. Gautier, N. Gallego-Planas, Yücel Sahin, E. Levillain, N. Mercier, P. Hudhomme, M. Masino, A. Girlando, V. Lloveras, J. Vidal-Gancedo, J. Veciana, C. Rovira, J. Org. Chem. 2004, 69, 2164; f) J. Calbo, J. Aragó, F. Otón, V. Lloveras, M. Mas-Torrent, J. Vidal-Gancedo, J. Veciana, C. Rovira, E. Ortí, Chem. Eur. J. 2013, 19, DOI: 10.1002/chem.201302910.

[14] a) X. Guégano, A. L. Kanibolotsky, C. Blum, S. F. Mertens, S.-X. Liu, A. Neels, H. Hagemann, P. J. Skabara, S. Leutwyler, T. Wandlowski, A. Hauser, S Decurtins, Chem. Eur. J. 2009, 15, 63; b) C. Goze, C. Leiggener, S.-X. Liu, L. Sanguinet, E. Levillain, A. Hauser, S. Decurtins, ChemPhysChem 2007, 8, 1504 c) M. Jaggi, C. Blum, N. Dupont, J. Grilj, S.-X. Liu, J. Hauser, A. Hauser, S. Decurtins, Org. Lett. 2009, 11, 3096.

[15] a) R. Pfattner, M. Mas-Torrent, I. Bilotti, A. Brillante, S. Milita, F. Liscio, F. Biscarini, T. Marszalek, J. Ulanski, A. Nosal, M. Gazicki-Lipman, M. Leufgen, G. Schmidt, L. W. Molenkamp, V. Laukhin, J. Veciana, C. Rovira, Adv. Mater. 2010, 22, 4198; b) M. Mas-Torrent, C. Rovira, Chem. Rev. 2011, 111, 4833.

[16] H. Kobayashi, R. Kato, T. Mori, A. Kobayashi, Y. Sasaki, G. Saito, T. Enoki, H. Inokuchi, Mol. Cryst. Liq. Cryst. 1984, 107, 33.

[17] M. A. Beno, U. Geiser, A. M. Kini, H.-H. Wang, K. D. Carlson. M. M. Miller, T J. Allen, J. A. Schlueter, R. B. Proksch, J. M. Williams, Synth. Met. 1988, 27 , A209.

[18] P. C. W. Leung, T. J. Emge, M. A. Beno, H. H. Wang, J. M. Williams, V. Petrick, P. Coppens, J. Am. Chem. Soc. 1985, 107, 6184.

[19] J. M. Williams, T. J. Emge, H. H. Wang, M. A. Beno, P. T. Copps, L. N. Hall, K. D. Carlson, G. W. Crabtree, Inorg. Chem. 1984, 23, 2558.

[20] J. N. Demas, G. A. Crosby, J. Phys. Chem. 1971, 75, 991.

[21] D. Magde, R. Wong, P. G. Seybold, Photochem. Photobiol. 2002, 75, 327.

[22] Oxford Diffraction CrysAlisPro (Version 1.171.34.36), Oxford Diffraction Ltd. Yarnton, Oxfordshire, UK, 2010.

[23] A. Altomare, M. C. Burla, M. Camalli, G. Cascarano, C. Giacovazzo, A. Guagliardi, A. G. G. Moliterni, G. Polidori, R. Spagna, J. Appl. Crystallogr. 1999, 32, 115.

[24] G. M. Sheldrick, Acta Cryst. 2008, A64, 112.

[25] G. Horowitz, R. Hajlaoui, H. Bouchriha, R. Bourguiga, M. Hajlaoui, Adv. Mater. 1998, 10, 923 . 
